\title{
Spontaneous visual exploration during locomotion in patients with phobic postural vertigo
}

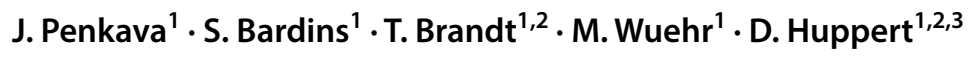

Received: 28 April 2020 / Revised: 23 July 2020 / Accepted: 7 August 2020 / Published online: 27 August 2020

(c) The Author(s) 2020

\begin{abstract}
Background Earlier studies on stance and gait with posturographic and EMG-recordings and automatic gait analysis in patients with phobic postural vertigo (PPV) or visual height intolerance (vHI) revealed similar patterns of body stiffening with muscle co-contraction and a slow, cautious gait. Visual exploration in vHI patients was characterized by a freezing of gaze-in-space when standing and reduced horizontal eye and head movements during locomotion.

Objective Based on the findings in vHI patients, the current study was performed with a focus on visual control of locomotion in patients with PPV while walking along a crowded hospital hallway.

Methods Twelve patients with PPV and eleven controls were recruited. Participants wore a mobile infrared video eyetracking system that continuously measured eye-in-head movements in the horizontal and vertical planes and head orientation and motion in the yaw, pitch, and roll planes. Visual exploration behavior of participants was recorded at the individually preferred speed for a total walking distance of $200 \mathrm{~m}$. Gaze-in-space directions were determined by combining eye-in-head and head-in-space orientation. Walking speeds were calculated based on the trial duration and the total distance traversed. Participants were asked to rate their feelings of discomfort during the walk on a 4-point numeric rating scale. The examiners rated the crowdedness of the hospital hallway on a 4-point numeric rating scale.

Results The major results of visual exploration behavior in patients with PPV in comparison to healthy controls were: eye and head positions were directed more downward in the vertical plane towards the ground ahead with increased frequency of large amplitude vertical orientation movements towards the destination, the end of the ground straight ahead. The selfadjusted speed of locomotion was significantly lower in PPV. Particularly those patients that reported high levels of discomfort exhibited a specific visual exploration of their horizontal surroundings. The durations of fixating targets in the visual surroundings were significantly shorter as compared to controls.

Conclusion Gaze control of locomotion in patients with PPV is characterized by a preferred deviation of gaze more downward and by horizontal explorations for suitable auxiliary means for potential postural support in order to prevent impending falls. These eye movements have shorter durations of fixation as compared to healthy controls and patients with vHI. Finally, the pathological alterations in eye-head coordination during locomotion correlate with a higher level of discomfort and anxiety about falling.
\end{abstract}

Keywords Phobic postural vertigo $\cdot$ Functional dizziness $\cdot$ Visual exploration $\cdot$ Eye movements $\cdot$ Head movements

J. Penkava and S. Bardins contributed equally to the work.

J. Penkava

josef.penkava@med.uni-muenchen.de

1 German Center for Vertigo and Balance Disorders (DSGZ), Ludwig-Maximilians-University, Marchioninistr. 15, 81377 Munich, Germany

2 Institute for Clinical Neurosciences, Ludwig-Maximilians-Un iversity, Munich, Germany

3 Department of Neurology, University Hospital, Ludwig-Maxi milians-University, Munich, Germany

\section{Introduction}

Phobic postural vertigo (PPV), a subtype of persistent postural-perceptual dizziness (PPPD), is a chronic functional disorder characterized by dizziness and subjective imbalance during stance and gait despite normal performance in vestibular and clinical balance tests [1-3]. This condition is the second most common diagnosis in an interdisciplinary tertiary outpatient dizziness unit (German Center for Vertigo and Balance Disorders) [4]. Neurophysiological analysis of 
stance and gait in PPV revealed an inadequate musculoskeletal stiffening with co-contraction of anti-gravity muscles [5-9]. The impairment of gait correlates with subjective fear of falling and balance confidence, although patients with PPV do not exhibit a higher rate of falls compared to healthy controls [10]. The stiffened postural control by muscle cocontraction is typical for PPV, but not specific, since stance and gait in individuals with visual height intolerance (vHI) or acrophobia exhibit similar stiffening of anti-gravity muscles when exposed to heights $[11,12]$. Walking of patients with PPV and of those susceptible to vHI is similarly characterized by a reduced speed, shorter steps with decreased cadence, and longer times in double support [8, 13]. Ocular motor behavior during stance and locomotion has also been tested in individuals with vHI when exposed to heights by use of a mobile infrared eye-tracking system with integrated inertial sensors for monitoring of head movements [14-16]. Visual exploration of the surroundings and the abyss during stance [14] and during walking at heights [15] when measured as 'gaze-in-space' behavior was significantly restricted in susceptible subjects whereas non-susceptible subjects freely explored the entire visual field and the abyss.

The current study is focused on visual exploration of patients with PPV during locomotion. This is of relevance for the pathophysiological interpretation of the motor behavior in both disorders. In vHI, the combined pattern of reduced mobility of legs, neck, and eyes was interpreted as an atavistic motor reaction (primitive reflex) to the phobic stimulus of height [16]. The question for the current investigation is whether the typical impairments of stance and gait control are also accompanied by a restriction of eye and head movements in patients with PPV.

\section{Methods}

\section{Subjects}

Twelve patients with PPV (5 females, age: 28-86 years, mean 57.2 years) and eleven healthy controls without any psychiatric, neurologic, vestibular, or balance disorders (6 females, age: $23-52$ years, mean 30.0 years) participated in the study. The diagnosis of PPV was based on the established diagnostic criteria $[1,17,18]$. Each patient underwent a detailed diagnostic work-up including thorough historytaking, clinical-neurological examination, functional-vestibular testing including orthoptic examination, caloric irrigation, and video head-impulse test.

\section{Experimental setup and procedures}

The main walkway of the University Clinic (about $450 \mathrm{~m}$ long) with shops and cafés on one side (Fig. 1a) was used as the experimental site for studying visual exploration of patients in crowded situations. Prior to the experiment, participants were equipped with a mobile infrared video eyetracking system consisting of goggles, a head-fixed camera, and a backpack with a recording laptop (EyeSeeTec GmbH, Munich, Germany, sampling rate of $220 \mathrm{~Hz}$ ) that measured eye movements in the horizontal and vertical planes (Fig. 1b). Eye movements were calibrated with a 5-point protocol. The calibration dots were projected from a laser unit attached to the head-fixed camera. Head orientation and motion in the yaw, pitch, and roll planes were measured with an inertial measurement unit (IMU) containing a triaxial accelerometer, gyroscope, and magnetometer (APDM, Inc.,

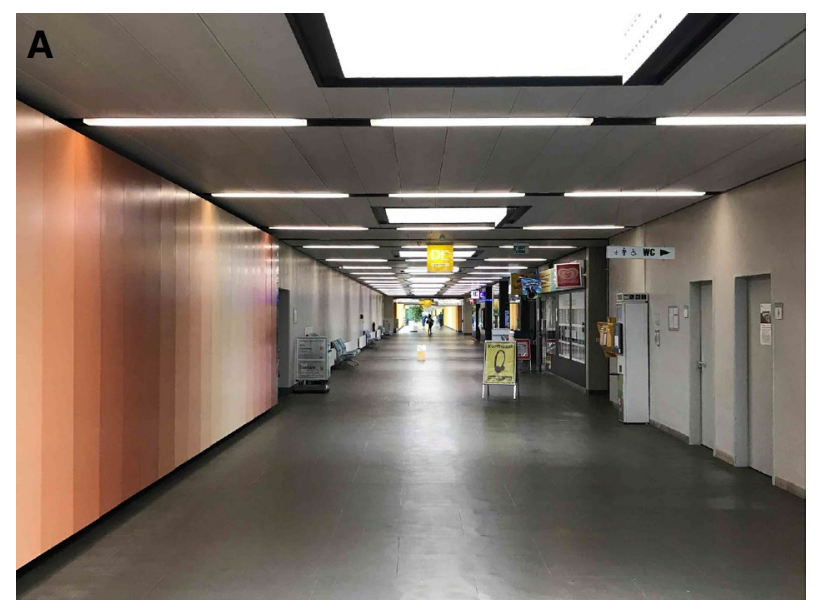

B

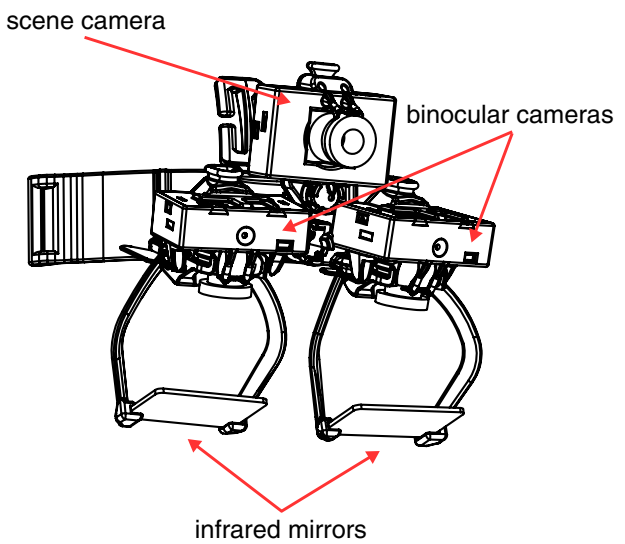

Fig. 1 a Participants walked at a self-paced speed on a hospital hallway for a total distance of $200 \mathrm{~m}$ separated by 4 recording blocks with intermittent breaks. b Visual exploration behavior (i.e., head and eye-in-head orientation and motion) was recorded by a mobile infra- red video eye-tracking system, consisting of goggles, a head-fixed camera, a head-fixed inertial measurement unit, and a backpack with a recording laptop 
Portland, OR, sampling rate of $128 \mathrm{~Hz}$ ). The eye tracker and inertial measurement unit recordings were synchronized by an external analog trigger signal (NI USB 6008, National Instruments).

During the experiment, participants were asked to walk at a self-paced speed for a given distance without any advice on how to visually explore their surroundings. The visual exploration behavior of participants was subsequently recorded four times, for a total walking distance of $200 \mathrm{~m}$. The time required in seconds to cover this distance was measured. Repeated trials were performed to examine potential habituation effects. After accomplishing the four recordings, participants were asked to rate their feelings of discomfort on a 4 -point numeric rating scale $(0=$ no, $1=$ minor, $2=$ medium, $3=$ intense). The crowdedness of the hallway during recordings was estimated by the examiner on a 4-point numeric rating scale $(0=$ empty, $1=$ little, $2=$ moderately, $3=$ highly crowded).

\section{Data analysis}

Data were stored for off-line analysis and analyzed with MATLAB (The Mathworks Inc. Version 2019b). Head orientation (with respect to the central perspective vanishing point of the walkway) and head angular velocity in the horizontal (yaw) and vertical (pitch) planes were calculated based on the IMU recordings. Head orientation estimates derived from IMU recordings were calibrated at the beginning of recordings based on manually identified fixed points in the scene camera recording. Eye movement data (from the left eye) was processed to identify fast phases (saccades) and slow phases (fixations, smooth pursuit, vestibulo-ocular reflex), respectively. For this purpose, eye velocity was calculated by 3-point differentiation and subsequent Gaussian low-pass filtering using a cut-off frequency of $30 \mathrm{~Hz}$. Fast phases were detected automatically using a threshold of $100 \%$ s of maximal (peak) eye velocity. The onset and offset of each saccade were defined by a threshold of 5\% of saccade peak velocity. Recording periods that contained eye blink artifacts were excluded from the analysis. The horizontal and vertical position of each saccade endpoint was calculated with respect to the central perspective vanishing point of the walkway. Durations of fixation were calculated as the intervals between separate fast phases of eye movements. Gaze-in-space directions were determined by combining head orientation and eye-in-head orientations. Walking speeds of patients and controls were calculated based on the trial duration and the total distance covered.

\section{Statistical analysis}

Descriptive statistics are reported as mean $\pm \mathrm{SD}$. Differences of visual exploration behavior between patients and healthy controls were assessed by a linear mixed model with the factors group (healthy vs. patients) and trial on the following outcome measures: walking speed, subjective discomfort and walkway crowdedness, mean and SD of head orientation, mean angular head velocity, mean and SD of eye orientation, and fixation duration. The relationship between the visual exploration characteristics in patients and both the individual degrees of discomfort and the level of walkway crowdedness was analyzed by Spearman's rank correlation. Results were considered significant at $p<0.05$. Statistical analysis was performed using SPSS (Version 25.0; IBM Corp., Armonk, NY).

\section{Results}

The amount of people present in the experimental environment varied slightly between different recording days; however, the average level of crowdedness did not differ between recordings in patients and healthy controls (Fig. 2b). While healthy participants did not experience any discomfort during the experiment, patients walked at a slower pace $(p=0.002$; Fig. 2c) and frequently reported feelings of discomfort while walking along the walkway $(p<0.001$; Fig. 2d). Subjective imbalance and discomfort in patients were linked to objectively measurable alterations in their visual exploration behavior. Patients' average head and eye-inhead orientation was directed more downwards $(p<0.001$; Fig. 3). The tendency to direct gaze-in-space more downwards (Fig. 4) was accompanied by an increased range of vertical head and eye movements $(p<0.001)$, which enables the patients to visually screen the straight-ahead direction from time to time. Patients further exhibited increased angular head velocities particularly in the horizontal plane $(p=0.041)$.

The average duration of visual fixations was considerably reduced in patients compared to healthy controls $(p=0.005$; Fig. 3f). Alerted visual exploration behavior did not show any habituation effects during the course of the four repeated walks.

Between individual patients, both the level of subjective discomfort and the level of walkway crowdedness determined further characteristic alterations, in particular with respect to a more vivid visual exploration in the horizontal plane (Fig. 5). Accordingly, patients reporting a higher level of discomfort exhibited an increased range $\left(R^{2}=0.61\right.$; $p=0.035)$ and velocity $\left(R^{2}=0.61 ; p=0.037\right)$ of horizontal head movements as well as an increased horizontal range of eye-in-head orientations $\left(R^{2}=0.59 ; p=0.045\right)$. Analogously, a higher level of walkway crowdedness during experiments was associated with increased horizontal head velocities $\left(R^{2}=0.62 ; p=0.031\right)$. 

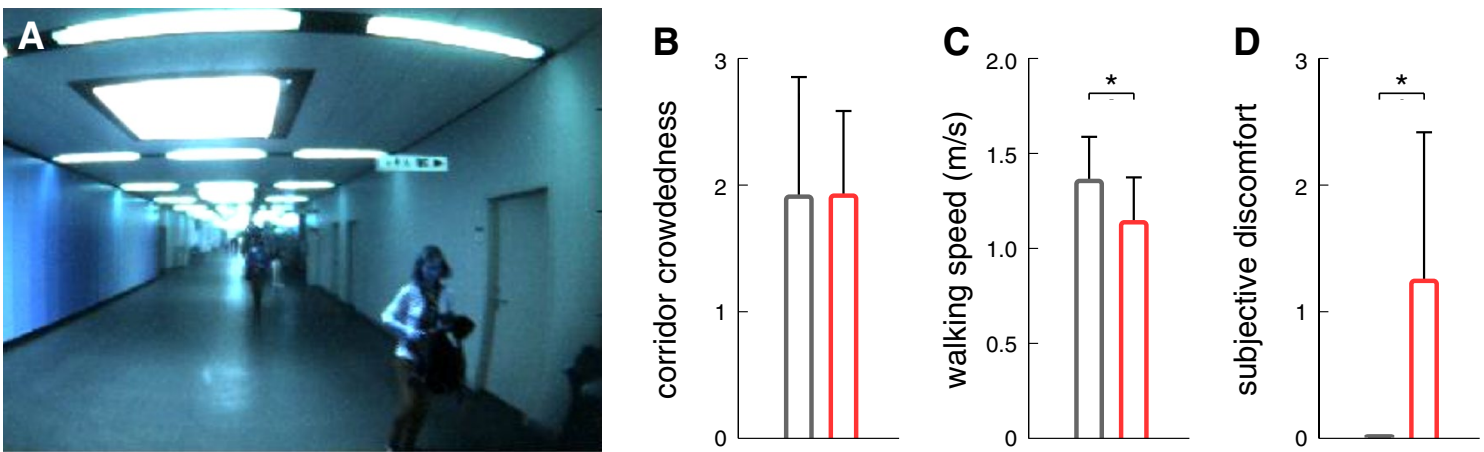

Fig. 2 a Exemplary view of the visual surroundings during an experimental trial. Comparison of $\mathbf{b}$ the level of crowdedness of the corridor during individual trials, $\mathbf{c}$ walking speed, and $\mathbf{d}$ levels of discomfort between patients with PPV (red bars) and healthy controls (gray bars) on a 4-point numeric rating scale. Despite equally crowded scenery on average across individual recordings, patients walked considerably slower and frequently reported feelings of discomfort, imbalance, or dizziness
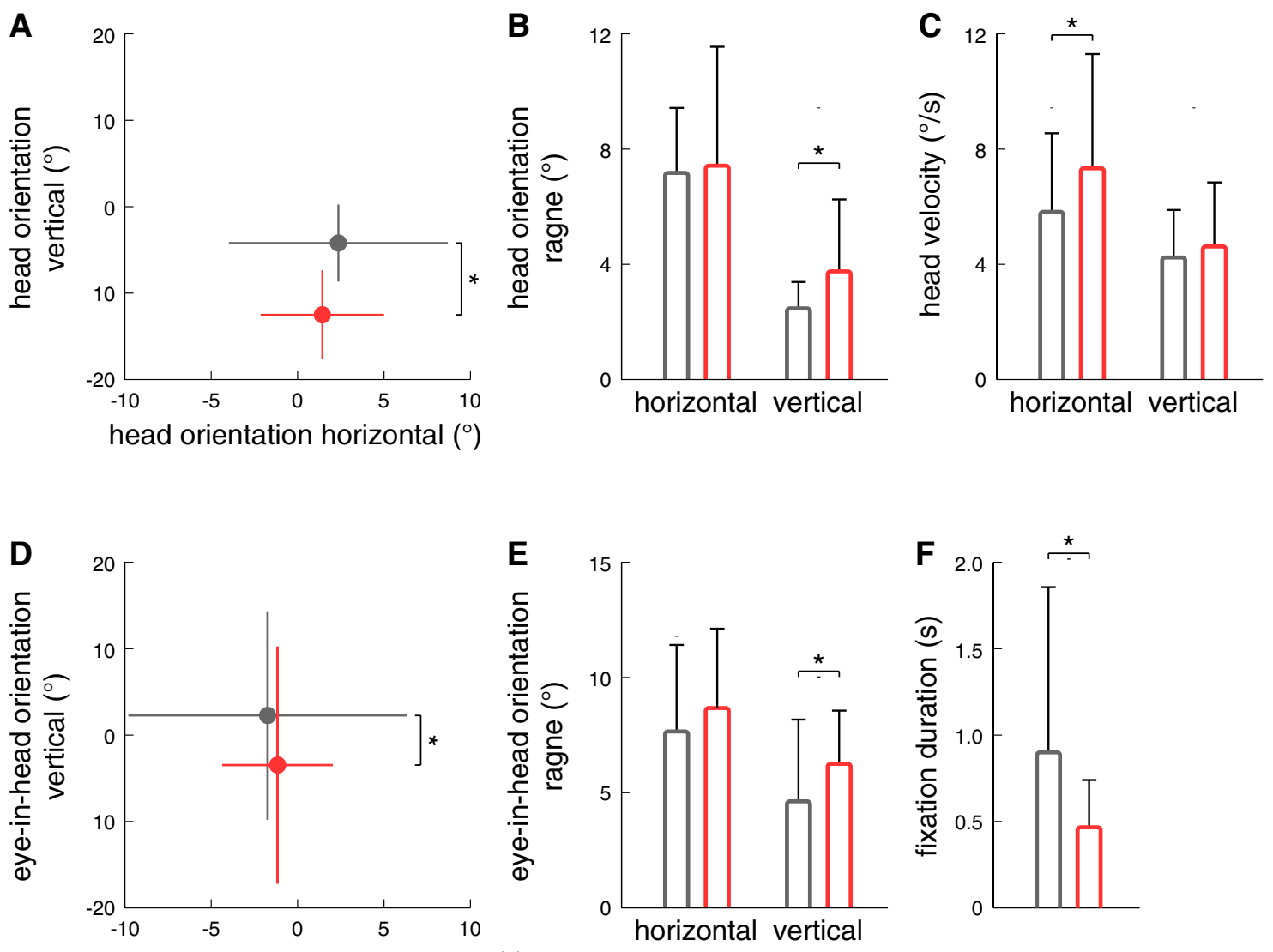

eye-in-head orientation horizontal $\left({ }^{\circ}\right)$

Fig. 3 Comparison of a mean and $\mathbf{b}$ range of head orientations, $\mathbf{c}$ mean head velocity, $\mathbf{d}$ mean and e range of eye-in-head orientations, and $\mathbf{f}$ fixation duration during walking between patients with PPV (red dots, bars) and healthy controls (gray dots, bars). During walking, eye and head positions of patients were directed more downward in the vertical plane towards the ground ahead with increased frequency of large amplitude vertical orientation movements towards the destination, the end of the floor straight ahead and an overall shorter fixation duration 


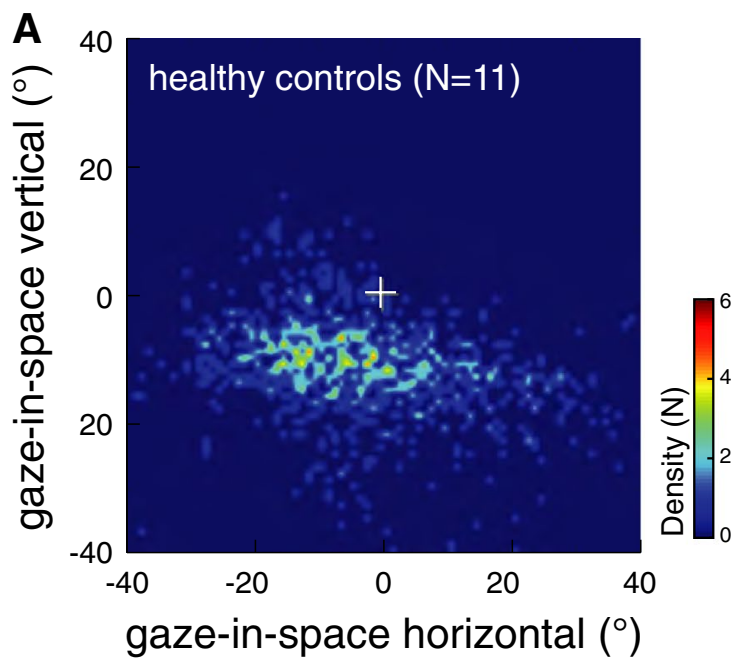

Fig. 4 Comparison of gaze-in-space behavior in a healthy controls and patients with PPV (b). Density plots represent fixations of environmental structures with combined head and eye-in-head movements during walking. The number of participants ( $\mathrm{N}$; coded by color) fixating identical targets (resolution of $1^{\circ}$ horizontally and vertically) cen-

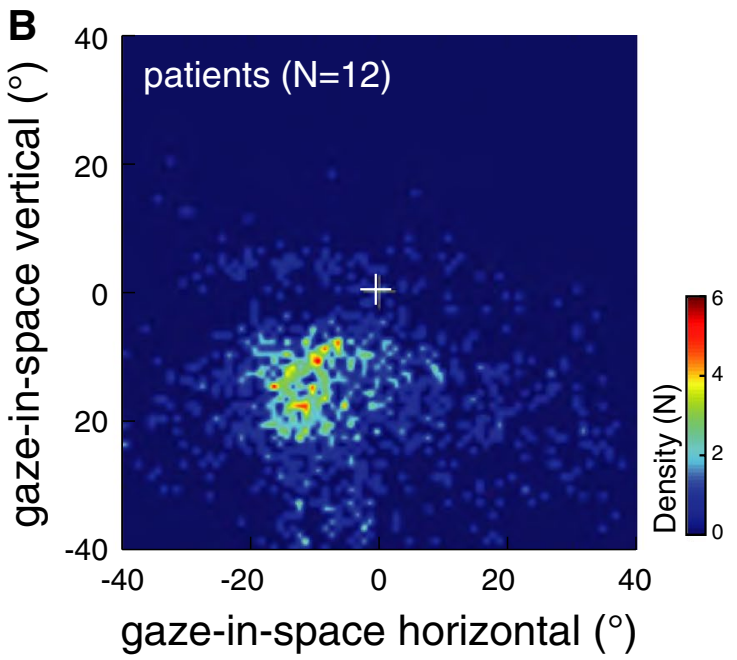

tered around the central perspective vanishing point of the walkway (white cross) are depicted. Patients directed their gaze more along the vertical plane with a preference for downward orientations towards the ground ahead
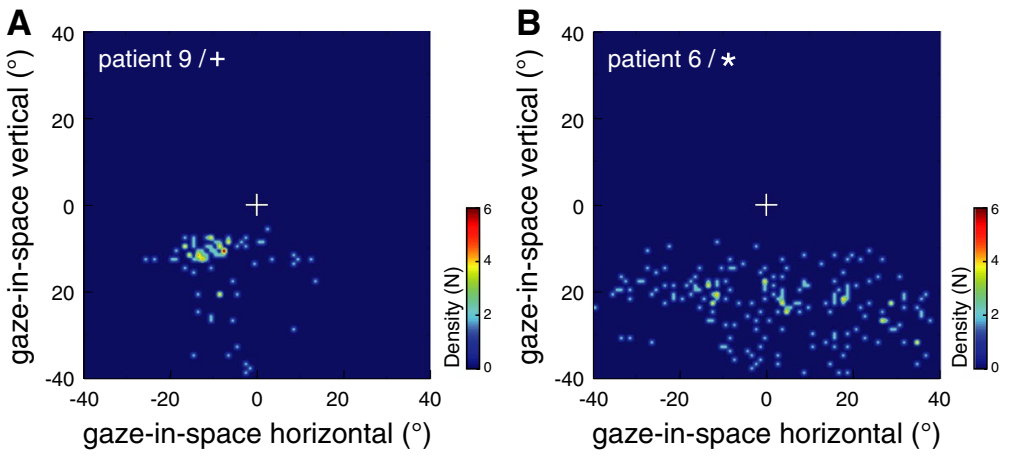

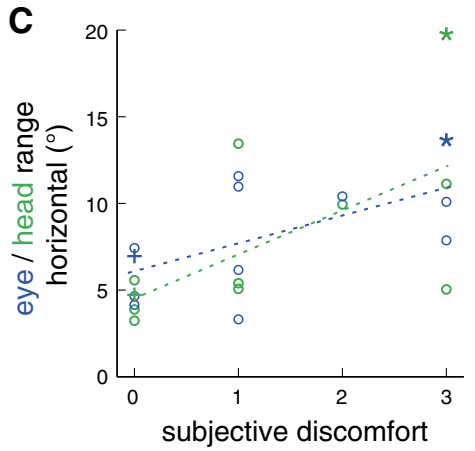

Fig. 5 Exemplary gaze-in-space behavior in a a patient with PPV reporting no discomfort (patient 9/+) compared to b a patient with PPV reporting intense discomfort (patient 6/*) during the experiment. Density plots represent fixations of environmental structures with combined head and eye-in-head movements during walking. The number of fixations ( $\mathrm{N}$; coded by color) focusing on identical targets (resolution of $1^{\circ}$ horizontally and vertically) centered around the

\section{Discussion}

In PPV patients, the analysis of visual exploration by eye and head movements during straight ahead locomotion in a crowded hospital hallway revealed significant differences to healthy controls as well as to previous reports on visual exploration behavior in subjects susceptible to vHI. Major differences to healthy controls were: eye and head positions were directed more downward in the vertical plane towards the ground ahead with increased frequency of large amplitude vertical orientation movements towards central perspective vanishing point of the walkway (white cross) are depicted. c Correlation between individual levels of subjective discomfort on a 4-point numeric rating scale and the range of horizontal eye and head orientations in patients with PPV. Particularly anxious patients exhibited a more or less pronounced nervous visual exploration of their horizontal surroundings to a degree that depended on their level of subjectively reported discomfort

the end of the ground straight ahead. Particularly patients that reported high levels of discomfort exhibited a more or less pronounced visual exploration of their horizontal surroundings with staccato-like eye-movements, which can be interpreted as a nervous visual exploration. Major differences of visual exploration compared to subjects susceptible to vHI were: eye and head movements were less restricted in PPV for vertical and horizontal planes and durations of fixation times were significantly shorter. In the following, we will first shortly summarize earlier findings of stance and gait parameters in both conditions and 
then discuss the characteristics and differences of visual exploration behavior.

\section{Stance and gait in PPV and vHI}

In patients with PPV, posturographic and EMG measurements of muscular activity during free upright stance revealed a pathological increase of body sway activity and an inadequate co-contraction of anti-gravity leg and neck muscles, resulting in a stiffening of body posture. This continuous anxious control of posture which is linked to muscle co-contractions $[5,6,11]$ leads to a kind of vicious circle $[7,9,16]$. Distraction of the patients by mental dual-tasking normalizes leg muscle activity and balance [9]. In healthy subjects and in subjects susceptible to vHI, exposure to heights causes similar alterations of postural control. It has been shown by Carpenter and colleagues in healthy subjects that increased postural threat by standing on elevated surfaces in the laboratory causes musculoskeletal stiffening of postural control [19] associated with changes in vestibulo-spinal reflexes [20]. The stiffening of anti-gravity muscles could also be found in subjects susceptible to vHI when exposed to real or virtual heights on an open escape balcony $[11,12]$. Thus, the above described motor pattern is typical, but not specific, since it holds for both anxiety-related conditions, PPV and vHI.

The same is true for the characteristic gait patterns in both conditions. The gait of patients with PPV is characterized by slow speed, reduced cadence and stride length, and increased double support [8], a pattern earlier described for gait changes in healthy subjects exposed to an increased postural threat [21-23]. The gait at heights of subjects susceptible to vHI and acrophobia showed similar features as that found in patients with PPV. It is reminiscent of a strategy of cautious gait control that healthy persons adopt to avoid falls when walking on ice. Anxiety appears to be the critical symptom that causes the typical motor behavior, since improvements could be observed by cognitive dual-tasking at heights which reduces the actual anxiety level [13].

\section{Visual exploration behavior during locomotion in PPV compared to vHI}

Vision has a major role within the multisensory balance control during stance [24, 25] and gait [26]. During locomotion, a coordination is necessary between the biomechanics of the bipedal gait cycle and gaze-in-space that gathers the spatial information required for the maintenance of the direction of movement and to determine safe locations for foot placements [27]. The previous literature on the role of visual gait control about upcoming footholds emphasizes regular ground fixations at two step lengths ahead [28-30]. The constant time of looking ahead was determined to be
$1.5 \mathrm{~s}$ for avoidance of hazardous obstacles independent of the terrain conditions [31,32]. Gait analyses by full-body kinematics combined with simultaneous recording of eye tracking revealed that on flat terrain the role of vision is modest with ground fixations occurring only during about half of the walking time [27]. This is in agreement with earlier findings by Pelz and Rothkopf [33]. The results of visual exploration in patients with PPV in a hallway in the hospital with a smooth surface without obstacles showed inadequate gait control with eye-in-head orientation mainly directed more downwards as compared to healthy controls, whose gaze was directed relatively higher with respect to the surroundings. This may be related to the increased fear of falling in PPV patients who adopt an inappropriate strategy which healthy persons only use while walking on unsafe terrain. Large amplitudes of vertical gaze-in-space movements reflect the continuous changes between the two fixations of the ground two steps ahead and the destination of locomotion straight ahead. Patients appear to feel the need to visually screen the straight-ahead direction from time to time. This vertical exploration of the surroundings had also been observed in subjects susceptible to vHI during locomotion at heights [15]. In both conditions, the preferred vertical exploration of the surroundings is anxiously driven to avoid either "falling down" on the ground in PPV or "falling off" a cliff in vHI [16].

In PPV patients, visual exploration in the horizontal plane was characterized by nervous, staccato-like eye and head movements scanning the surroundings. This was especially observed in those patients that reported high levels of discomfort presumably reflecting their anxiety. This is in contrast to persons with $\mathrm{vHI}$, in whom the explored area was restricted towards the wall of the building and the handrail, but who simultaneously avoided looking towards the open side of the balcony [15]. Durations of target fixations were different in both conditions: they were considerably reduced in patients with PPV compared to healthy controls, whereas in $\mathrm{vHI}$ there was a tendency to longer durations of fixations [15]. This eye-head orientation pattern in PPV patients is best explained by an anxious search for suitable auxiliary means for potential postural support. Analogously, a similar kind of nervous horizontal visual search has been found in other neurological disorders, in which ocular motor control is driven by anxiety, such as in patients with cognitive disturbances of spatial orientation in navigational tasks. Patients with amnestic mild cognitive impairment, for instance, showed an increased frequency of horizontal eye movements and fixations, obviously to regain orientation by searching for visual landmarks to find the correct walkway to the envisaged goal $[34,35]$. This horizontal visual search was reflected by activations of the pontine ocular motor center for horizontal eye movements in FDG-PET immediately following the navigational tasks [34]. Patients with 
chronic bilateral vestibulopathy, which also impairs spatial memory and navigation [36-39], showed a higher frequency of horizontal fixation saccades, particularly at junctions or crossings of walkways [40]. With respect to acrophobia, which is psychiatrically defined as a specific phobia [41, 42], the exploratory behavior of patients with specific phobias such as animal or social phobias must be mentioned [16]. The general visual exploration pattern in patients with specific phobias when exposed to the threatening stimulus is that of a "hypervigilance-avoidance" exploration. Subjects with spider phobias, for example, detect the critical spiders faster in the initial presentation phase, but subsequently shift their view more often away from the spiders as compared to controls [43-45]. The same was described for subjects with an injection phobia [46] or social phobias [47]. The latter form of avoidance behavior may present an alternative explanation for the pattern of eye and head movements in PPV-patients in the sense of avoiding looks from oncoming individuals. One important limitation of the study might bias the present findings: due to the different age distributions between patients and controls, we cannot exclude the possibility that differences in patients' visual exploration behavior may be partly explained by age-related effects.

In conclusion, gaze control of locomotion in patients with PPV is characterized by a preferred deviation of gaze more downward towards the ground and by nervous horizontal explorations in search of possible support to avoid impending falls. These eye movements have shorter durations of fixations as compared to healthy controls and patients with vHI. The pathological alterations in eye-head coordination during locomotion correlate with a higher level of discomfort and anxiety about falling. The exploration pattern in PPV patients is mainly different to that of patients with vHI in two aspects: amplitude and frequency of eye-head movements are increased in PVV with shorter duration of fixations of visual exploration. However, postural control of stance and gait are very similar in both conditions.

Acknowledgements We thank Katie Göttlinger for copy-editing the manuscript.

Funding Open Access funding provided by Projekt DEAL. The work was supported by the German Federal Ministry of Education and Research (BMBF, Grant code 01EO1401) and the Hertie Foundation.

\section{Compliance with ethical standards}

Conflicts of interest On behalf of all authors, the corresponding author states that there is no conflict of interest. S. Bardins is a shareholder of EyeSeeTec $\mathrm{GmbH}$, manufacturer of the eye-tracking equipment used in the study.
Ethical standard statement The patients gave their informed written consent to participate in the study, which was performed in accordance with the ethical standards laid down in the 1964 Declaration of Helsinki and its later amendments.

Open Access This article is licensed under a Creative Commons Attribution 4.0 International License, which permits use, sharing, adaptation, distribution and reproduction in any medium or format, as long as you give appropriate credit to the original author(s) and the source, provide a link to the Creative Commons licence, and indicate if changes were made. The images or other third party material in this article are included in the article's Creative Commons licence, unless indicated otherwise in a credit line to the material. If material is not included in the article's Creative Commons licence and your intended use is not permitted by statutory regulation or exceeds the permitted use, you will need to obtain permission directly from the copyright holder. To view a copy of this licence, visit http://creativecommons.org/licenses/by/4.0/.

\section{References}

1. Brandt T (1996) Phobic postural vertigo. Neurology 46:1515-1519

2. Dieterich M, Staab JP, Brandt T (2016) Functional (psychogenic) dizziness. Handb Clin Neurol 139:447-468

3. Dieterich M, Staab JP (2017) Functional dizziness: from phobic postural vertigo and chronic subjective dizziness to persistent postural-perceptual dizziness. Curr Opin Neurol 30:107-113

4. Brandt T, Dieterich M (2017) The dizzy patient: don't forget disorders of the central vestibular system. Nat Rev Neurol 13:352-362

5. Krafczyk S, Schlamp V, Dieterich M, Haberhauer P, Brandt T (1999) Increased body sway at $3.5-8 \mathrm{~Hz}$ in patients with phobic postural vertigo. Neurosci Lett 259:149-152

6. Querner V, Krafczyk S, Dieterich M, Brandt T (2000) Patients with somatoform phobic postural vertigo: the more difficult the balance task, the better the balance performance. Neurosci Lett 285:21-24

7. Wuehr M, Pradhan C, Novozhilov S, Krafczyk S, Brandt T, Jahn K, Schniepp R (2013) Inadequate interaction between open- and closed-loop postural control in phobic postural vertigo. J Neurol 260:1314-1323

8. Schniepp R, Wuehr M, Huth S, Pradhan C, Brandt T, Jahn K (2014) Gait characteristics of patients with phobic postural vertigo: effects of fear of falling, attention, and visual input. J Neurol 261:738-746

9. Wuehr M, Brandt T, Schniepp R (2017) Distracting attention in phobic postural vertigo normalizes leg muscle activity and balance. Neurology 88:284-288

10. Schlick C, Schniepp R, Loidl V, Wuehr M, Hesselbarth K, Jahn K (2016) Falls and fear of falling in vertigo and balance disorders: a controlled cross-sectional study. J Vestib Res 25:241-251

11. Wuehr M, Kugler G, Schniepp R, Eckl M, Pradhan C, Jahn K, Huppert D, Brandt T (2014) Balance control and anti-gravity muscle activity during the experience of fear at heights. Physiol Rep 2(2):e00232. https://doi.org/10.1002/phy2.232

12. Wuehr M, Breitkopf K, Decker J, Ibarra G, Huppert D, Brandt T (2019) Fear of heights in virtual reality saturates 20 to $40 \mathrm{~m}$ above ground. J Neurol 266:80-87

13. Schniepp R, Kugler G, Wuehr M, Eckl M, Huppert D, Pradhan C, Huth S, Jahn K, Brandt T (2014) Quantification of gait changes in subjects with visual height intolerance when exposed to heights. 
Front Hum Neurosci. https://doi.org/10.3389/fnhum.2014.00963 .eCollection 2014

14. Kugler G, Huppert D, Schneider E, Brandt T (2014) Fear of heights freezes gaze to the horizon. J Vest Res 24:433-441

15. Kugler G, Huppert D, Eckl M, Schneider E, Brandt T (2014) Visual exploration during locomotion limited by fear of heights. PLoS ONE 9(8):e105906

16. Brandt T, Kugler G, Schniepp R, Wuehr M, Huppert D (2015) Acrophobia impairs visual exploration and balance during standing and walking. Ann NY Acad Sci 1343:37-48

17. Staab JP, Eckhardt-Henn A, Horii A, Jacob R, Strupp M, Brandt T, Bronstein A (2017) Diagnostic criteria for persistent posturalperceptual dizziness (PPPD): consensus document of the committee for the classification of vestibular disorders of the Barany Society. J Vestib Res 27:191-208

18. Brandt T, Huppert D, Strupp M, Dieterich M (2015) Functional dizziness: diagnostic keys and differential diagnosis. J Neurol 262:1977-1980

19. Carpenter MG, Frank JS, Silcher CP, Peysar GW (2001) The influence of postural threat on the control of upright stance. Exp Brain Res 138:210-221

20. Horslen BC, Dakin CJ, Inglis JT, Blouin JS, Carpenter MG (2014) Modulation of human vestibular reflexes with increased postural threat. J Physiol 592:3671-3685

21. Brown LA, Gage WH, Ploych MA, Sleik RJ, Winder TR (2002) Central set influences on gait. Exp Brain Res 145:286-296

22. Delbaere K, Sturnieks DL, Crombez G, Lord SR (2009) Concern about falls elicits changes in gait parameters in conditions of postural threat in older people. J Gerontol A Biol Sci Med Sci 64:237-242

23. Tersteeg MC, Marple-Horvat DE, Loram ID (2012) Cautious gait in relation to knowledge and vision of height: is altered visual information the dominant influence? J Neurophysiol 107:2686-2691

24. Paulus W, Straube A, Brandt T (1984) Visual stabilization of posture. Physiological stimulus characteristics and clinical aspects. Brain 107:1143-1163

25. Peterka RJ (2002) Sensorimotor integration in human postural control. J Neurophysiol 88:1097-1118

26. Logan D, Kiemel T, Dominici N, Cappellini G, Ivanenko Y, Lacquaniti F, Jeka JJ (2010) The many roles of vision during walking. Exp Brain Res 206:337-350

27. Matthis JS, Yates JL, Hayhoe MM (2018) Gaze and the control of footr placement when walking in natural terrain. Curr Biol 28:1224-1233

28. Patla AE, Vickers JN (1997) Where and when do we look as we approach and step over an obstacle in the travel path? NeuroReport 8:3661-3665

29. Patla AE (1998) How is human gait controlled by vision. Ecol Psychol 10:287-302

30. Matthis JS, Fajen BR (2014) Visual control of foot placement when walking over complex terrain. J Exp Psychol Hum Percept Perform 40:106-115

31. Barton SL, Matthis JS, Fajen BR (2017) Visual regulation of gait: Zeroing in on a solution to the complex terrain problem. J Exp Psychol Hum Percept Perform 43:1773-1790
32. Matthis JS, Barton SL, Fajen BR (2017) The critical phase for visual control of human walking over complex terrain. Proc Natl Acad Sci USA 114:E6720-E6729

33. Pelz JB, Rothkopf C (2007) Oculomotor behavior in natural and man-made. In: Van Gompel RPG, Fischer MH, Murray WS, Hill RL (eds) Eye movements: a window on mind and brain. Oxford, Elsevier, pp 661-676

34. Schöberl F, Pradhan C, Irving S, Buerger K, Xiong G, Kugler G, Kohlbecher S, Engmann J, Werner P, Brendel M (2020) Realspace navigation testing differentiates between amyloid-positive and -negative aMCI. Neurology 94:e861-e873

35. Schöberl F, Zwergal A, Brandt T (2020) Testing navigation in real space: contributions to understanding the physiology and pathology of human navigation control. Front Neural Circuits 14:6. https ://doi.org/10.3389/fncir.2020.00006

36. Brandt T, Schautzer F, Hamilton DA, Brüning R, Markowitsch HJ, Kalla R, Darlington C, Smith P, Strupp M (2005) Vestibular loss causes hippocampal atrophy and impaired spatial memory in humans. Brain 128:2732-2741

37. Kremmyda O, Hüfner K, Flanagin VL, Hamilton DA, Linn J, Strupp M, Jahn K, Brandt T (2016) Beyond dizziness: virtual navigation, spatial anxiety and hippocampal volume in bilateral vestibulopathy. Front Hum Neurosci 10:139. https://doi.org/10.3389/ fnhum.2016.00139

38. Brandt T, Zwergal A, Glasauer S (2017) 3-D spatial memory and navigation: functions and disorders. Curr Opin Neurol 30:90-97

39. Dobbels B, Peetermans O, Boon B, Mertens G, Van de Heyning P, Van Rompaey V (2019) Impact of bilateral vestibulpathy on spatial and nonspatial cognition: a systematic review. Ear hear 40:757-765

40. Schöberl F, Pradhan C, Grosch M, Brendel M, Trapp C, Jahn K, Bartenstein P, Brandt T, Dieterich M, Zwergal A (2020) Allocentric real-space navigation deficits in bilateral vestibular failure. In review.

41. World Health Organisation (1993) The ICD-10 classification of mental and behavioral disorders. Clinical description and diagnostic guidelines. WHO, Geneva

42. American Psychiatric Association (2013) Diagnostic and statistical manual of mental disorders: DSM-5, 5th edn. American Psychiatric Publishing, Washington DC

43. Hermans D, Vansteenwegen D, Eelen P (1999) Eye movement registration as a continuous index of attention deployment: data from a group of spider anxious students. Cognit Emot 13:419-434

44. Pflugshaupt T, Mosimann UP, von Wartburg R, Schmitt W, Nyffeler T, Müri RM (2005) Hypervigilance-avoidance pattern in spider phobia. J Anxiety Disord 19:105-111

45. Rinck M, Becker ES (2006) Spider fearful individuals attend to threat, then quickly avoid it: evidence from eye movements. J Abnorm Psychol 115:231-238

46. Armstrong T, Hemminger A, Olatunji BO (2013) Attentional bias in injection phobia: overt components, time course, and relation to behavior. Behav Res Ther 51:266-273

47. Bögels SM, Mansell W (2004) Attention processes in the maintenance and treatment of social phobia: hypervigilance, avoidance and self-focused attention. Clin Psychol Rev 24:827-856 